Canadian Journal of Family and Youth, 8(1), 2016, pp 213-237

ISSN 1718-9748 @ University of Alberta

http://ejournals.library.ualberta.ca/index/php/cjfy

\title{
Relational Care for Youth in North American Culture: A Case Study in Nova Scotia
}

\author{
Leah J. Crowell
}

\begin{abstract}
This article is a case study of relational care for youth in Canada. It examines some of the factors that contribute to and influence approaches to practice and levels of care for youth. This inquiry also provides an enriched understanding of some of the issues youth in care may face and highlights some of the nuanced intervention needs of youth that those working with youth should know. Through practical examples taken from observations of interactions and relationships between youth and practitioners in a residential setting, practice approaches and ensuing levels of care are assessed against the characteristics and objectives of relational care. This article adds to the literature on child and youth care practice with youth, relational practice in the field and research on child and youth care work within the residential milieu. It may also contribute to the literature on the criminalization of youth as well as rehabilitation and reform needs of at risk youth and be of use to educators, child and youth care practitioners, social workers, and the training institutions of these professionals.
\end{abstract}

Leah Crowell is a mature student who returned to university after almost two decades to pursue a degree in Child and Youth Studies at Mount Saint Vincent University. Leah graduated with her BA in Child and Youth Studies in the spring of 2015 and is currently a graduate student and Teaching Assistant at Dalhousie University where she is working on her Master's thesis in Sociology. She is also currently working as a Research Assistant on a project that is investigating the impacts of any familial members' incarceration on children. For her thesis, Leah is looking at the educational needs and supports for youth and young adults who are incarcerated in Nova Scotia. Her research interests include but are not limited to: the social determinants of child and youth development, educational approaches and interventions, youth justice, crime, ideology and social policy, life course and developmental transitions, age and risk factors, lifestyle determinants and health, and affective and emotional development which, all connect back to an overarching concern for the social welfare of young people. 
Commentary

\section{Introduction}

According to leading scholars in the field of child and youth care (CYC), the fundamental element of the practice is self (Garfat \& Charles, 2007; Stuart, 2013; Gharabaghi, 2010).

Scholars from disciplines such as psychology and social work have also written about the importance of the use of genuine self and relationship in therapeutic care (Ungar, 2011; Ivey, Ivey \& Zalaquett, 2011).The ultimate use and culmination of self in CYC work comes "through sharing self in bi-directional relationships.” When "“other' experiences genuine connectedness with another the door opens to give an alternative way of being in the world" (Garfat \& Charles, 2007, p.6), at which point therapeutic care can begin. A uniquely interpersonal profession, the day-to-day work of CYC practitioners is said to position child and youth care workers to be "ideally situated to be among the most influential of healers and helpers in a person's life" (Garfat \& Fulcher, 2011, p. 7). That said, I do not present these descriptions of CYC practice to suggest that this potential is only possible for CYC practitioners. Instead, I propose that this potential, to be an 'influential healer' easily extends to other professions that are centered on interacting with young people, such as educators, social workers and councilors. Regardless, it is from within the profession of child and youth care that I have experienced both the profound power, nay, magic of employing self in relational practice with young people and the unnecessary harm that can come from not using self to be relational when working with youth.

Throughout my experiences as both a community involved parent and as a child and youth care practitioner I have noticed a general and significant difference in the tone and attitude adults take when addressing or responding to older children, adolescents and young adults, as opposed to when talking with younger children. To some degree this is normal; the way in which we communicate with infants and younger children, the way a culture imparts language to 
Commentary

children, is a natural processes (Parke, Gauvain \& Schmuckler, 2010). I am not referring to the natural progression towards speaking in a more mature tone to older children. Rather, what I am hearing are tones and comments that seem to indicate a lack of patience, kindness, and respect and suggest that the speakers have forgotten that youth and young adults are still learning and developing and require support from the adults who model pro-social behaviour within their daily interactions and relationships. In addition to this change in tone, I have noted that many adults appear to withdraw or implicitly impose a position of authority when talking to young people between the ages of 12 and 21. More specifically, among adults in general and those who work with youth, I have over time observed a limited use of "self" to connect with youth, limited effort to communicate or engage and connect with young people, and an absence of the use of relationship to build rapport with youth. I became very interested in exploring what might be contributing to this kind of depersonalized, detached care for youth. To this end, whenever I have observed adults interacting with youth in this way I have paid particular attention to how it played out.

The following is a case study that emerged through the observations I made during an undergrad practicum in 2015 at a residential home for male youth who, for various reasons, were considered to be at risk. I will use a series of interactions that took place to analyze this 'detached care.' This is not to criticize practitioners who may not utilize self or relational approaches in their practice and who, in turn, keep a distance from their clients; rather, it is meant to be a respectful yet critical analysis of some of the factors that may be impeding child and youth care workers and other helping professionals from connecting with young people, to consider the repercussions of this kind of care on youth development, to ponder the implications for training and development of the helping professions, and to consider what is needed to 
Commentary

cultivate more relational practice. My aim is to illustrate the importance of relational practice and demonstrate how small efforts to be relational can play an important part in a youth's development. The presentation of this incident is rich in detail in order to convey, and linger in, the complex space of the interpersonal-relational moments between adults/practitioners and youth and to facilitate an analysis of the intricacies of the use of self and relational practice. A key goal of this residential program was to foster independence, and the mission of the organization included 'eliminating problems youth face' through its residential support centres. The young person in this story, let's call him Joe, was seventeen and fairly new to Nova Scotia. The staff person involved in this situation, I'll call him Scott, was in his mid-twenties. I first met Joe on the day I had my interview for the placement. He interrupted my meeting with the manager to tell the manager he wasn't feeling well and to ask if he could call his mother. He said he wanted to call her because he was missing her and was worried about her health. The manager told him that he could call his mother but asked him to be quick as the call would incur daytime long distance charges and said "thank you" rushing off to use the phone in another room.

\section{The Story: Youth and Care}

On the first night of my practicum only four boys were living in the residence, and none of them were home when I arrived. It was the first time I met Scott. As part of my orientation I had to read all of the boys' admittance forms, which had background information about each youth, and their log books, which were separate notebooks kept for each resident that the staff wrote in daily. Most of the boys had been there for less than two months. Joe had come to Nova Scotia from another province to meet and try to connect with his biological father. 
As I read the logs, I took note of the most recent things going on with the residents. I noticed that recent entries in Joe's book reiterated that he had been "complaining of not feeling well" a few days prior to my shift and that one of the other boys had a "heated argument over chores" with staff a few days prior. Shortly after I had finished reading the logs, Scott gave me a quick update on everyone's whereabouts. He was brief on all the youth except Joe. His update was a somewhat animated account of the fact that Joe "supposedly went to the hospital" to get checked out and included Scott rolling his eyes about Joe seeking medical attention. He went on to tell me that Joe had wanted staff to accompany him to the hospital and again rolled his eyes at the mention of a youth requesting such support. Scott then told me not to worry because "staff here doesn't have to do that kind of thing," adding "these guys are almost men and they need to figure it out." This indicated to me that Scott was not considering developmental science, child and youth care theory, or the context of the situation, Joe's situation-seventeen years old, new to the city, and alone.

When Joe returned home he entered the common room where Scott and I were sitting watching television and immediately began to tell us about his visit to the doctor. He told us that the doctor said he had an ear infection but advised Joe not to use ear drops. When he finished, he appeared to pause to wait for Scott to comment. There was no response. Scott continued to stare at the television. Joe, still standing, shifted his posture and then commented that he didn't know what he was going to do because it was really bothering him. Again he seemed to pause for Scott to comment. This time I too was waiting for Scott to respond, look up, nod, or something. After a few seconds, without looking at Joe, Scott said, “Oh yeah” Joe continued, repeating himself a little, and said again, “I don't know what I'm going to do. It really hurts!”Again Joe appeared to be waiting for a comment. Scott did not respond. I may have only waited five seconds, though it 
Commentary

seemed a lot longer. I could not ignore Joe. I would not ignore anyone talking to me, as I believe that to do so would be rude and disrespectful, so I responded.

Joe turned to face me and we began to talk. I asked him when the earache started, if he had had an earache before and other miscellaneous questions such as whether he had been eating well. Scott stared at the television and did not engage in any part of this conversation. Based on his earlier comments I had the impression that he didn't buy Joe's story. Recalling that Joe's log book indicated his complaints of not feeling well were consistent for a few days at this point, it seemed to me that Joe deserved the benefit of the doubt. Considering context — that Joe was missing his mom - I thought that even if Joe's story about going to the doctor was embellished for attention, he might really need to connect with someone. So rather than "closing off" because of the possibility that this youth was telling stories, I listened to him, asked questions, and showed some concern. As our exchange ended Joe sat down to watch some television, and Scott got up and went into the office to, I suspect, log Joe's report of his visit to the hospital. I wondered what might be going on with Scott. Why didn't he respond to Joe? Did he not like Joe, or was it a matter of different personalities? Maybe he was suffering from burnout? As I sat taking notes and reflecting, I noted the clear lack of the use of self; there was no communication and no apparent intent to build rapport or a relationship with this youth. I wondered if Joe picked up on what appeared to be disregard for him and his health concerns as was implied by Scott's lack of response. Was Scott aware of how this may have felt to Joe? Regardless of what was behind it and whether it was conscious or unconscious, Scott's biases and judgments appeared to be impacting the level of care he was providing.

Deficiencies in care related to oversights like this highlight the importance of self and self-reflection in the child and youth care profession. As Burns (2012) explains, practitioners 
must reflect on how they interact and serve clients, asserting that aspects of self in youth care impact the happiness and mental health of the young people and their families. Burns acknowledges that the importance of self and the expression of self "places an awesome responsibility on the child and youth worker [to] uncover all the prejudices, biases, barriers, and impediments that prevent [us] from assisting children, youth and families” (Burns, 2012, p. 9). Having read this around the time of this incident, I was concerned that interactions like the one described above, although non-dramatic, could have some harmful effects on Joe. This brought me to wonder again about Scott and his background; did he have formal training in a helping profession? Was he taught about the value of reflection in CYC work? Could the use of reflection at the organizational level, in team and supervisor meetings, be an effective way to facilitate more mindful practice?

With Scott still in the office, Joe and I sat in the living room watching television. During this time Joe kept rubbing his ear and jaw. Supper had been on the counter; it was do-it-yourself donairs, but Joe requested a little help from me with his, and I complied. He only ate a little bit of supper and then returned to watch television while cupping and rubbing his ear. After making a tea and returning to the common room I asked him how the pain level was and he told me it felt like it was getting worse. He asked me if I knew of anything that would help the pain. I told him we could check with Scott about Tylenol, and before I finished my sentence he was standing up, asking if I would go with him to ask Scott for some Tylenol right away. I agreed and accompanied him to the staff room. Without even looking up Scott gave Joe some Tylenol and we left the office. Joe then asked me what else he could do for the pain, and I suggested that he drink some water and lay down for a while. He got a glass of water and headed up to his room. Joe woke about four hours later and came back downstairs. I asked him how he was feeling and 
he said he had a great sleep, but the returning pain woke him. I told him I could relate and shared that I used to get bad earaches when I was a kid, adding that I found they can be worse than headaches. Joe extended the conversation to wonder what causes earaches and what might help relieve them. I told him that I like to look for natural things, like food, that might help with common ailments and gave him the example of carrots and beets being recognized as natural anti-inflammatories. This interested him and he asked me where he could find out more about it. I told him that the library would probably have some books on the topic and that the Internet would also have a lot of information, warning that it takes patience and time to sift through it all. To this I added that there is no "hard science" in supporting the pursuit of natural remedies and talked to him about the placebo effect. I also shared with him that for me, whether it is a placebo effect or not, if I think it works and feel better from eating carrots or beets, "I will take it, even if it is in my mind!" He was enjoying the conversation and was asking lots of questions. Then, acknowledging that he was not allowed to use a computer by himself, Joe asked if I would sit with him for a few minutes to look up care for earaches, and I told him I would ask Scott when he came out of the office.

After about twenty minutes of waiting for Scott to come out of the office, Joe told me his earache was back in full force and he was eager to use the computer. He asked if we could go talk to Scott, and I said yes. As we approached the open door of the staff room, I started to ask, "Hey Scott, can Joe and I go online for a minute to..." and before I could finish the sentence, Scott interrupted abruptly, saying, "No, you can't do that. The boys are not allowed on our computers, and you can't prescribe anything to them, we are not doctors!" This was all said quickly and rather loudly and conveyed great displeasure or annoyance that I had suggested such a thing. Shocked at his response and feeling like an inexperienced student I stammered and 
Commentary

gently responded that I understood that we could not prescribe anything and clarified that I just wanted to look up natural ways to alleviate ear pain. I also added that I thought they could sit close by while we searched something online for them. Scott reiterated that this was not an option, restating that we can't prescribe anything because "we are not doctors." Without pausing, he also explained that it was his personal computer, adding that no youth were to use his computer. We awkwardly lingered for a couple seconds, which felt like five long minutes, and before I could step away Joe responded by telling the Scott that he needed something because his ear was really hurting again, at which point Scott, in a very loud voice, asked, "What do you want me to do about it, Bud?" Joe appeared to be both embarrassed and angry and stood staring at Scott. Scott stared back. I stepped away to remove the audience and allow them to continue their "discussion."

Moments later as Joe came out of the office I heard Scott close their conversation by calling out, "You can have more Tylenol before you go to bed." While I sat there in the living room I felt both angry and deflated about what had just happened. In recalling that there was typically only one staff on at any given time, I now felt concerned about the care Joe was receiving from Scott when no one was around. I wondered if this was why Joe had asked me to accompany him to ask Scott for Tylenol. Maybe this was how Scott always spoke to him. As I went over the incident in my mind, I was really upset that Scott treated us as he did and I considered reporting his unprofessional conduct to the manager immediately. But I knew that wasn't the answer and that I needed to talk to Scott about it first. Wrapping my head around the circumstances of the situation I determined that regardless of how the conversation went with Scott, I knew what the priority was: that Joe was cared for and safe in the house. My mind was racing. I tried to distract myself with the television but instead I sat painfully aware of the fact 
that half way through the first shift of my practicum I was in conflict with a staff member that required I advocate for a youth that I didn't really know yet.

Joe came back into the common room after the confrontation with Scott and sat, with an empty gaze, staring past the television out through the large window in the room. He sat like this for a while and when he finally got up I took his movement as an opportunity to break the silence and inquired if he was heading to bed. Looking past me, he nodded and with his hand up to his ear he left the room. I heard him go back and tell Scott he was going to go to bed; he got his Tylenol and went upstairs. While I sat in the living room by myself I returned to a deep state of reflection but not as a student, practitioner, or parent, simply as a human. I was genuinely concerned for this youth; away from family and alone in life's struggles at such a young age. At times, I was obsessing about what I could or should have done differently. He was treated so poorly simply because he asked for some support. It was unfair and unkind to treat him like that. It really bothered me that he went to bed feeling uncared for after first being disregarded and then passive-aggressively bullied — in a place that was supposed to be a safe home away from home. I thought about academic work on the caregivers' place in the residential milieu. Some even pose that we should see ourselves as entering the residents' space rather than the youth entering our workspace (Gharabaghi, 2010; Smith, 2009). This requires inquiry into how we can and should be respectful about being in their home space, but I think it would be safe to say that yelling at a youth who is seeking support, in front of others, would not be considered being respectful in someone's living space.

I was concerned that my attempt to build rapport as a step towards relational practice with this youth was futile or even worse, that my efforts created this situation of conflict for Joe. This sense of failure made room for self-doubt about my actions. It was my first night at the 
house; perhaps I was completely off-track to engage with and offer an "at risk" youth attention on my first shift. Thinking about some of the comments I've heard others make about working with youth I wondered if there was any merit to these attitudes; do immediate efforts to engage with youth position us at a disadvantage somehow? Does having a friendly, engaging and helpful approach make helping adults look weak in their eyes? Despite what colleagues' comments imply and in contrast to the stereotypical images of "at risk youth" as withdrawn rebels who don't want adults getting in their business, the literature on intervention research in resiliency, counselling, and child and youth studies validates that "relationship" is an important factor for success with adolescent risk takers and young offenders(Guilamo-Ramos, Jaccard, Dittus \& Bouris, 2006; Ungar, 2011). In the same vein, Clark (2001) gathered feedback from at risk youth in programs, and the feedback consistently indicated that youth need and want adults working with them and engage with them. Clark suggests that professionals "make a concerted effort to meet, quickly become familiar with, and even charm incoming participants" (Clark, 2001, p.25). Additional research showed a similar theme in that "youth's perceptions of the alliance rules when it comes to the outcome" (Clark, 2001, p.25; Guilamos-Ramos et al, 2006; Ungar 2011). Interestingly, despite the consistent evidence that supports relational practice in the literature, it seems that in the field relational practice is noticeably unsupported.

In a debrief with Scott an hour later, I told him I thought the youth were allowed to use computers when staff are present, adding that I also did not realize it was his personal computer. Scott seemed to appreciate this but went right into making judgmental and critical remarks about Joe. He reiterated earlier comments that "he is always complaining that something is wrong" and stated matter-of-factly that he was "just trying to get attention." Within a matter of minutes I had been warned to "be careful when talking to Joe," advised that he was "playing" me and that I 
Commentary

could not trust "anything these guys say," and told that he "always says he is sick, makes up stories, and has mental issues." I found these statements discriminatory and offensive and I was surprised that he shared these opinions with me. I later wondered if Scott thought he was helping me by warning me about working with "youth like Joe.” Ultimately Scott's behaviour and language was a violation of the Standards for Practice of North American Child and Youth Care Professionals, which state that practitioners will "ensure that services are sensitive to and nondiscriminatory of clients regardless of age...gender...mental or physical handicap, etc." (Stuart, 2009, Appendix B, p. 322). Although I knew this, I was not sure what to say in the moment. Having heard and addressed similar language in the past I knew what I was up against if he would even acknowledge that his remarks were discriminatory. Mindful of my status as a student on placement I decided to let the "debrief” trail off and end.

\section{Discussions with a mentor}

The next day on campus I visited Dr. Mucina's office to discuss the situation with him. I sought his counsel because he was the lead professor of youth work theory and practice in the Child and Youth Studies program I completed in Nova Scotia, and he was experienced with working with youth in the residential milieu. I explained to him what had happened and shared two of the main concerns I had about my actions: first, that I had helped Joe make his donair and that I worried that this move was incongruent with the program objectives of fostering independent living; and second, that I stepped outside of professional boundaries in talking to Joe about self-care and “self-medicating" by suggesting he research and consider natural remedies. In response to my concern about helping Joe prepare his meal, Dr. Mucina reminded me that many scholars in the field (and related disciplines) assert that being open and flexible to adjusting our interactions, 
Commentary

approaches, and intervention plans to consider the context and the individual needs of a client is a requirement for effective CYC and counselling practice (Garfat, 2011; Folari, 2011; Ungar, 2011; Stuart, 2009; Ivey, Ivey, \& Zalaquett, 2011). Moreover, he acknowledged that my decision to help Joe with supper was clearly derived from considering context as it was informed by my assessment of his apparent need to connect with someone based on Joe's previous disclosure about missing his family, and Dr. Mucina supported my decision to help. In addition, he referred to another scholar who talks of levels of support and consideration for the context of the situation and challenges practitioners to evaluate whether it is reasonable to enforce rigid expectations of independence by specifically asking if, even when fostering independent living, it is reasonable to expect young people to do everything themselves and not need or want any support (Smith, 2009)?

In regards to my offer to help Joe look for natural remedies for ear pain, Dr. Mucina contested that the life skills meant to be taught here were mediated within an ethics of care framework, utilized self in the sharing of personal perspectives, which offers the "other" an example of another way to be in the world, and again, took context into consideration. I reiterated my concern that many would argue that following organizational guidelines word for word and sticking to explicit role descriptions is good care. I explained that I saw rigid adherence to organizational/professional expectations as a huge impediment to the quality of care given and shared that I was feeling anxious about the issues and conflict I would face (or could cause) in opposing rigid adherence to checklists in favour of fluid and flexible practice use guidelines. I recounted consistent messages from coworkers and supervisors to be leery of giving special care under any circumstance and instead treat everyone exactly the same. Dr. Mucina asked, "If we decide to forgo any attempts at individualized care, like helping a youth navigate the Internet, to 
Commentary

hold to rules and avoid risk, what are we teaching? What kind of example does this give about teaching and learning, to prepare youth for future decision making?" In addition, Dr. Mucina did not think that what I proposed was "prescribing" anything and instead believed I was appropriately modeling self-care and critical thinking. We didn't have to look very hard to find support for this logic either; resiliency expert Michael Ungar also argues that we need to be able to teach skills like resource management, literacy and navigating technology (Ungar, 2011).

\section{The Story - Continued}

Returning to practicum on my next shift I was met by a young female practitioner. She was very friendly and we talked a lot before any of the boys came home. When Joe arrived home he joined us in the living room and we engaged him in some casual conversation. After a few minutes, the practitioner left to take a phone call in the office at which point Joe said he wanted to thank me for talking to him the other night and frankly disclosed to me that he had picked up on some "bad vibes" from certain staff. He then shared that he was starting to think there was something wrong with him, adding that he was trying to understand why the staff didn't seem to like him. At this point the staff person on shift returned from the office and cheerfully asked what we were talking about. Joe hesitated for a minute and then replied, very diplomatically, that "some staff, I won't name them" didn't talk to him very nicely and added that it "makes me really uncomfortable around the house." She stood there, apparently hesitant to respond. As though suspecting that she might have been questioning his claim, he turned to me and asked, "You saw it the other night, right?" Of course I validated this by affirming that I did witness what he was referring to, and I told him that I could understand why he might be feeling like that. My colleague was still quiet. 
Commentary

To position the conversation as fair and objective I also pointed out that sometimes staff may be having a bad day and this can come out in crankiness toward others. To this my colleague spoke up and said, "Yes, Scott must have been having a bad day." Joe didn't buy this though and insisted that he is usually cranky to everyone but "seems to be the worst when he deals with me." During most of the rest of the conversation the staff member was pretty quiet; I was mindful that she was in a challenging position as a junior practitioner in the house and therefore understood why she was reluctant to comment. For me, student or not, I could not deny Joe's intuition by being silent on this. His perceptions of Scott and now this staff member were very astute, and I did not want to add to his struggles by causing him to doubt himself or by diminishing how he was feeling. His disclosure answered my earlier question; he had picked up on Scott's initial disregard and attitude toward him, and it was affecting him by making him uncomfortable in his living space. Although this conversation didn't change anything for Joe, I now felt pleased that I had engaged with him as minimally as I had that first night, as it apparently gave him enough comfort to open up and share some of his concerns. That small, initial investment of talking to him when he came back from the doctor's office resulted in achieving an important objective of practice - a "sense of collaboration with the youth, an active and respected level of engagement that allows for a youth voice to be heard"(Gharabaghi, 2010, p. 9; Ungar, 2011). And now that his voice had been heard I could actively support and advocate for him.

Since a staff member was present for much of the conversation with Joe that night I assumed that there would be something about it in the log book, and I expected that my advocacy work would begin with the manager as I assumed she would want to talk to me since I had witnessed the interactions that spurred Joe to disclose his concerns. To my dismay, when I 
arrived on my next shift she was rushing to an appointment, and when I asked her about finding some time to talk about "Joe's report" in the log book she looked confused. Acknowledging she had to leave I told her I would be happy to come in early to talk to her about it the next day. She paused for a moment, looked at her watch, and then asked me to join her in her office for a quick chat right then. As I followed her into the office, I asked myself a lot of questions. First of all, why wasn't anything about Joe's report in the log book? This was a significant statement that came with a witness's account that was worthy of being noted, wasn't it? Did staff think this was too small an issue to address? Was I making a big deal out of a minor infraction? And was this my only opportunity to discuss the situation and seek supervision within the organization, as she was on her way out the door?

As we sat down she asked me what happened. Feeling rushed to respect her appointment I quickly gave her the gist of what Joe had said about being treated unkindly and feeling uncomfortable in the house. She nodded as I told her the story, and when I finished she said, "Well Joe is very sensitive and has a tendency to take everything personally." I reiterated that I was witness to the encounter and told her anyone who was treated like that would have been put off. I wondered to myself how staff could know what Joe's tendencies were considering the short a period of time he had been in residence and how little he was around the house. She then explained that some staff choose to keep a safe distance from the youth and asked if maybe I was being overly sensitive. During the discussion the manager also suggested that perhaps I was not reading the staff or the youth accurately and assured me that these skills "would come in time." She also cautioned that working with youth is different than working with younger children, adding that they will often play one practitioner against another. Throughout the conversation I sensed a general disregard for Joe's report, and I was not surprised that the defenses cited 
Commentary

including a gentle suggestion that he may have mental health issues. When she finished I disclosed more specifics and asserted that Joe had articulated almost exactly what I had observed during the exchange. The details helped the manager shift toward giving Joe's report some consideration, and she shared that Scott was dealing with some stress in his personal life. I expressed my empathy for Scott and told her I was also concerned about Joe's stress, considering his challenging life situation, and ended by returning to the main issue, that a youth in the house was uncomfortable due to treatment from staff. The manager agreed that this needed to be addressed, said she would take it from there, and thanked me for the feedback.

\section{The Story: Finishing practicum}

Between the four CYC workers and the various shifts, I only worked with Scott a couple more times over the remainder of my placement. Joe and I continued to talk periodically throughout my time at the house and had some good, meaningful conversations. In one of these conversations I told him that for a seventeen-year-old he was pretty skilled at reading social situations and people's "vibes," as he put it. In discussing it, he quickly identified a negative aspect of the skill and said, "Yah, it kinda sucks because I can feel it when people don't like me or are being rude and trying to hide it." He also thanked me for bringing it up and said that having me identify it as a skill was helpful and changed the way he thought of himself. Despite our rapport, Joe was very quiet some nights. He was grappling with a lot of uncertainty, and from what I could tell the last decade of his life had been really rough. For the rest of my shifts I brought my laptop in so I could use it with the boys if they wanted. We watched Netflix together a couple times, I turned the huge dining room table into a ping pong table one night, and sometimes we just drank tea and talked. Near the end of practicum when Joe heard that my last 
Commentary

shift was rapidly approaching he jumped up out of his seat and said, "What? You're leaving? You can't leave! Who am I going to talk to about everything? Who is going to help me think about things differently? You are so positive, you can't leave!” I was really touched by his reaction. As it turned out, Joe left the house before I finished practicum. He moved back to his home province with the intent of reuniting with his family, reconciling past differences and going back to school to get a trade.

\section{Summary and Discussion}

In one of my first classes with Dr. Mucina, he asked students if they thought they thought they could show respect and/or love for the youth they would eventually work with. I'm not sure what he saw from his vantage point in the class but as I looked around the class for signs of response, I saw more than a few students shaking their heads no. To this he asserted that good care requires that we show the youth we work with both love and respect. Although many other professors and scholars would support this claim, it intrigues me because the students' responses were more indicative of the prevailing attitudes and discourses on youth that I have encountered in the field. In other courses too, student responses conveyed a pathology perspective which included holding tight to matters of individual responsibility and accountability that was void of considerations of context and favoured "corrective" or punitive interventions over supportive and needs sensitive interventions. The extent to which these attitudes impact CYC practice,

specifically scholars in disciplines such as education and criminology, has highlighted how North American culture and media criminalize youth and propagate negative perceptions and stereotypes of youth as thugs and delinquents (Giroux, 2014; Hogeveen \& Woolford, 2006; Noella, Parmar, \& Stovall, 2014). Regardless of the frequency with which we encounter tainted 
Commentary

attitudes toward youth they are present in our culture and they appear to permeate the CYC workplace. The presence of this attitude in the helping profession appears to be a key determinant of the provision of relational care.

It seems to me, based on my experience, that the western cultural ethos is not particularly conducive to facilitating or valuing relationship, kindness or empathy in youth work (or towards any “other") and instead encourages and values independence and autonomy. This can result in a deficient provision of care, one that is limited by unreasonable expectations and faulty assumptions that can often play out to impose a form of isolation or exile on children and youth that sounds like "grow up,"“figure it out yourself" or "suck it up." Although I can appreciate the need to foster autonomy, this objective should be complemented with the need to teach and model care, healthy relationships and interdependency. Developmental science tells us that the human brain does not stop developing until we are into our twenties (Cauffman, 2012; McMahan, 2009; Parke et al., 2010; Passer, Smith, Atkinson, Mitchell \& Muir, 2008).On top of that, in the west, the transition from adolescence into young adulthood is thought to be one of the most challenging times in our development (Cauffman, 2012; Twenge, 2011; Giroux, 2014). Practitioners need to have this in mind in their everyday work with youth to assist and support in the adaptation of compassion into their practice.

In the same vein, the helping professional must, for the sake of each youth, consider the social ecology of their clients. In order to understand a youth and assess their needs, practitioners must employ the sociological imagination in their practice as it directs us to consider the history and social-ecological context of a young person's life (Krueger \& Stuart, 1999; Ungar, 2011). Given that young people who are living in residential care typically enter the system because 
Commentary

they are facing adversity and are in a difficult life transition, these youth in care, perhaps more than anyone, really need help figuring it out or finding ways to cope and "suck it up."

A Practitioner's perception of youth varies from region to region, between service providers, and again from practitioner to practitioner. Of course the values, beliefs and theories a practitioner is influenced by, will also contribute to attitudes. Another common theme I've heard in the logic that practitioners cite for not engaging with youth and/or troubled children infers a need for control, or fear about a lack thereof, an "it's us or them" or "get the upper hand first" stance, a belief that you have to command respect from the youth and 'let them know who's boss." For her article "Professional Boundaries in Child and Youth Care Work"(2009), Nancy Marshall collected data from practitioners about the main fears that keep professional boundaries top of mind: fear of being physically harmed, fear of being sued, and fear of damage to their professional reputation. Although I acknowledge that we must be mindful of these very real fears, we must not let them dominate in shaping our approach to care. Combined with negative stereotypes of youth, interpersonal boundary management guided by fear is positioned to deter and impede relational care for youth. Finally, organizational policies and professional expectations may also discourage practitioners from providing relational care. Three of the four practitioners at the organization where I did my placement declared that they practiced from a “detached stance." They talked about the need to protect self and disclosed that they didn't feel empowered by the organization to consider the individual youth or the context of the situation in making decisions. In fact, they admitted that they refrained from making any decisions that would stray from checklists or protocol for fear of it backfiring. In addition, they interpreted theory and literature in the field that supports the idea of boundaries and healthy detachment (and rightly so) as further support for their detached stance. 
Commentary

Bowlby \& Ainsworth's work on attachment theory states that early bonds with caregivers play a crucial role in personality and temperament development (Bowlby \&Ainsworth, 1991). These theorists also suggest that attachment behaviours are a "major component of human behavioral equipment, that has protection as its biological function not only in childhood but throughout life, which could be understood in terms of evolution theory" (Bowlby \&Ainsworth, 1991). Additional research on attachment theory suggests that later and ongoing attachment bonds, healthy or problematic, also have the potential to influence later life outcomes and personal development. Vygotsky's socio-cultural theory also asserts that our social relationships and culture are integral to our learning and development (Penuel \& Wertsch, 1995; Parke et al., 2010; Passer et al., 2008). Moreover, having a social element built into intervention programs that include mentors or consistent role models has been shown to be more effective in building resiliency and have longer lasting impact for youth than programs that do not specifically have a social element (De Villiers \& Van den Burg, 2012; Peacock-Villada, DeCelles \& Banda 2007; Pierce \& Shields, 1998). This supports the notion that our social relationships, even when they are fleeting (e.g., in a three-month stay in a residential home or a six-month after school program), have the potential to positively impact development. Practitioners who have had formal training are aware of the influence they can have and understand that influence infers responsibility to connect with the youth they work with; however, there are still many practitioners working in Canada without formal training. This creates a rift or disconnect between coworkers and approaches to practice that must be addressed to ensure care for youth is consistently appropriate. This puts trained practitioners in a challenging position, to somehow confront practice that is lacking theoretical support. 
Commentary

Finally, this case study brought about some important questions regarding training programs: What skills do practitioners require in order to be able to identify where flexibility can be exercised? How is education in boundaries and ethics affecting practitioners' levels of fluidity or rigidity of practice? What skills and knowledge do practitioners need to be able to address and manage conflicting approaches to practice and interpersonal matters with youth, with coworkers? Recent studies suggest that people who have experienced adversity, stress and maltreatment as children may exhibit improved cognitive skills in tasks involving ecologically relevant stimuli, including improved speed and accuracy in identifying emotions in people's faces (Frankenhuis \& De Weerth, 2013; Mittal et al., 2015). This has huge implications for practitioners and echoes the importance of training on social ecological frameworks in practice and the use of self, relationship, and genuine communication in order to be prepared to appropriately react and respond to clients in ways that are sensitive to the their life experiences. Through the development of more specialized courses aimed at developing the skill sets required by those in the helping professions, new practitioners will be better prepared and more comfortable in providing opportunities for positive relationships and interactions with caring adults for those who are most in need of connection and support: youth who are "at risk" in this challenging phase of development.

Education is clearly the strongest venue through which we can work to build the collective capacity for relational care among Canada's CYC practitioners. To this end I have imagined professional Canadian CYC programs (and Social Work and Psychology programs) collaborating to create a new, mandatory course (in the same way that statistics courses are a requirement) of enriched training on the use of self, communication, relationship, and reflection. The course would have a strong experiential component so that students could practice these 
Commentary

skills and extensive case study work that would challenge them to consider the importance of taking the individual, their background, and the current context into consideration as a necessary part of their decision-making process. Courses like this would further facilitate not only the development of relational skills, but provide students with practice in the application of relational theory and skills. Students must be challenged to consider and question the dominant discourse and cultural influences, as well as the cultural and personal history/background of the person or population they are working with. Such training/courses are conducive to the development of mindful practice that encourages students to employ the sociological imagination to recognize and consider all the elements of a youth's environment.

\section{Closing Comments}

Along the way I have been assured that I will toughen up. I don't want to. I am guided by a "concern for care" directive that requires a soft, fluid, relational approach—not toughness. By allowing practice to focus simply on engaging with the youth, you make space for them to become comfortable and interested in talking with you. When young people open up to us, we simply need to listen sincerely, be our genuine selves, suspend our biases and any judgment of the youth, consider their background, acknowledge that they are the expert on their life experience, search for signs of strength and aptitudes that you might be able to cultivate, and collaborate with them to figure out what they need. Simple? No, it's a skill that must be developed. But it can develop to be a magical craft. I offer this story as encouragement to practitioners that even small actions, like have a handful of open conversations with a young person over a period of a couple of months can make a difference to the youth we work with and to our workplace culture, even if only in small gains or for short periods of time. 
Commentary

\section{References}

Ainsworth, M.D.S. \& Bowlby, J. (1991). An ethological approach to personality development. American Psychologist, 46(4), 333-341.

Burns, M. (2012). The Self in child and youth Care: A celebration. Kingston, ON: Child Care Press.

Cauffman, E. (2012). Aligning justice system processing with developmental science. Criminology \& Public Policy, 11(4), 751-758.

Clark, M.D. (2001). Influencing positive behavior change: Increasing the therapeutic approach of juvenile courts. Federal Probation, 62(1), 18-27.

De Villiers, M. \& van den Berg, H. (2012). The implementation and evaluation of a resiliency programme for children. South African Journal of Psychology 42(1), 93-102.

Follari, M.L. (2011). Foundations and best practices in early childhood education:_History, Theories and Approaches to Learning $2^{\text {nd }}$ ed.. New Jersey: Pearson Education Inc.

Frankenhuis, W., \& De Weerth, C. (2013). Does early-life exposure to stress shape or impair cognition? Current Directions in Psychological Science, 22(5), 407-412.

Garfat, Thom and Charles, Grant. (2007). How am I who I am? Self in child and youth care practice. Recreational Child and Youth Care Practice, Fall 2007, Vol. 20, Issue 3, 6-16.

Garfat, T., \& Fulcher, L. (2011). Characteristics of a relational child and youth care approach. Relational Child and Youth Care Practice, 24(1-2), 7-19.

Gharabaghi, K. (2010). Professional issues in child and youth care practice. London: Routledge.

Giroux, H. (2014). "Punishment Creep and the Crisis of Youth." From Education to Incarceration: Dismantling the School-to-Prison Pipeline. ProtoView, 1(49), 69-85.

Guilamo-Ramos, V., Jaccard, J., Dittus, P., \& Bouris, A.M. (2006). Parental Expertise, Trustworthiness and Accessibility: Parent-adolescent communication and adolescent risk behavior. Journal of Marriage and Family, 68(5), 1229-1246.

Hogeveen, B., \& Woolford, A. (2006). Critical criminology and possibility in the neo-liberal ethos. Canadian Journal of Criminology and Criminal Justice, 48(5), 681-701.

Ivey, A.E., Ivey, M.B., \& Zalaquett, C.P. (2011). Intentional interviewing \& counselling. $7^{\text {th }}$ Ed. Belmont, CA: Brooks/Cole.

Krueger, M., \& Stuart, C. (1999). Context and competence in work with children and youth. Child and Youth Care Forum, 28(3), 195-204. 
Marshall, N. (2009). Professional boundaries in child and youth care work. Relational Child and Youth Care Practice, Winter, Vol. 22, Issue 4, p. 37.

McMahan, I. (2009). Adolescence. Boston: Pearson Education Inc.

Mittal, C., Griskevicius, V., Simpson, J., Sung, S., Young, E., \& Kawakami, K. (2015). Cognitive adaptations to stressful environments: When childhood adversity enhances adult executive function. Journal of Personality and Social Psychology, 109 (4), 604621.

Mucina D.D. (2015). Personal communications, March 17 - April 30, 2015. Halifax NS.Noella, A.J. II, Parmar, P. \& Stovall, D., (Eds.). (2014). From Education to Incarceration. New York: Peter Lang.

Parke, R.D., Gauvain, M., \& Schmuckler, M. (2010). Child Psychology: A_Contemporary Viewpoint_3rd Canadian ed. Halifax: McGraw-Hill Ryerson.

Passer, W.M., Smith, R.E., Atkinson, M.L., Mitchell, J.B., \& Muir, D.W. (2008). Psychology: Frontiers and Applications $3^{\text {rd }}$ Canadian ed. Halifax: McGraw-Hill Ryerson.

Peacock-Villada, P., DeCelles, J. \& Banda, P.S. (2007). Grassroot Soccer resiliency pilot program: Building resiliency through a sport-based education in Zambia and SouthAfrica. New Directions for Youth Development. No. 116, 141-154.

Penuel, R. William, \& Wertsch, V. James. (1995). Vygotsky and identity formation: A sociocultural approach. Educational Psychologist, 30(2), 83-91.

Pierce, L.H. \& Shields, N. (1998). The Be a Star Community Based After School Program: Developing resiliency in high risk preadolescent youth. Journal of Community Psychology, Vol. 26, No. 2, 175-183.

Smith, M. (2009). Rethinking residential child care: Positive perspectives. London: Polity Press.

Stuart, C. (2013). Foundations of child and youth care. 2nd edition. Dubuque, IA: Kendall Hunt.

Twenge, J.M. (2011). Generational differences in mental health: Are children and adolescents suffering more, or less? American Journal of Orthopsychiatry, Vol. 81, No.4, 469-472.

Ungar, M. (2011). Counselling in challenging contexts: Working with individuals and families across clinical and community settings. California: Brooks/Cole. 